\title{
Reconfiguration and closure of lobe flux by reconnection during northward IMF: possible evidence for signatures in cusp/cleft auroral emissions
}

\author{
M. Lockwood ${ }^{1,2}$ and J. Moen ${ }^{3}$ \\ ${ }^{1}$ Rutherford Appleton Laboratory, Chilton, UK \\ ${ }^{2}$ Also Guest Lecturer at the University Courses on Svalbard \\ ${ }^{3}$ University Courses on Svalbard, Longyearbyen, Svalbard, Norway \\ Received: 26 May 1998 / Revised: 3 November 1998 / Accepted: 27 November 1998
}

\begin{abstract}
Observations are presented of the response of the dayside cusp/cleft aurora to changes in both the clock and elevation angles of the interplanetary magnetic field (IMF) vector, as monitored by the WIND spacecraft. The auroral observations are made in $630 \mathrm{~nm}$ light at the winter solstice near magnetic noon, using an all-sky camera and a meridian-scanning photometer on the island of Spitsbergen. The dominant change was the response to a northward turning of the IMF which caused a poleward retreat of the dayside aurora. A second, higher-latitude band of aurora was seen to form following the northward turning, which is interpreted as the effect of lobe reconnection which reconfigures open flux. We suggest that this was made possible in the winter hemisphere, despite the effect of the Earth's dipole tilt, by a relatively large negative $\mathrm{X}$ component of the IMF. A series of five events then formed in the poleward band and these propagated in a southwestward direction and faded at the equatorward edge of the lower-latitude band as it migrated poleward. It is shown that the auroral observations are consistent with overdraped lobe flux being generated by lobe reconnection in the winter hemisphere and subsequently being re-closed by lobe reconnection in the summer hemisphere. We propose that the balance between the reconnection rates at these two sites is modulated by the IMF elevation angle, such that when the IMF points more directly northward, the summer lobe reconnection site dominates, re-closing all overdraped lobe flux and eventually becoming disconnected from the Northern Hemisphere.
\end{abstract}

Key words. Magnetospheric physics (magnetopause, cusp and boundary layers; solar-wind-magnetosphere interactions) . Space plasma physics (magnetic reconnection)

Correspondence to: M. Lockwood

e-mail: M.Lockwood@rl.ac.uk

\section{Introduction}

The possibility that reconnection would take place between northward-pointing interplanetary magnetic field (IMF) and the geomagnetic field in the tail lobes, poleward of the magnetic cusps, was first suggested by Dungey (1963). His concept was that a draped IMF field line in the magnetosheath could reconnect simultaneously at the sunward edge of the tail lobes of both hemispheres, thereby producing a closed dayside field line. This is now understood to be just one of several possibilities, but unlikely to take place in practice. Russell (1972) pointed out that a more likely situation was that the draped northward IMF would reconnect in one hemisphere only, thereby driving a circulation of open flux within that polar cap. A catalogue of other topological possibilities was presented by Cowley (1981, 1983). The northward-pointing sheath field could, in principle, reconnect with either open or closed geomagnetic flux: this reconnection could occur in both hemispheres simultaneously, but for different sheath field lines, or at different times for any one sheath field line. The first observational evidence that this northward-IMF lobe reconnection does indeed take place was sunward flow in the polar cap ionosphere, first deduced from geomagnetic observations (Maezawa, 1976) and confirmed by direct observations of the flow (e.g. Burke et al., 1979; Cumnock, 1992) and of the associated fieldaligned current pattern (Zanetti et al., 1984). The sunward flow can give a net negative transpolar voltage (where positive voltage is associated with a dawn-todusk electric field, i.e. antisunward flow) (Freeman et al., 1993) and reverse latitudinal dispersion of cusp ions (Woch and Lundin, 1992) and can exist in both polar caps (Reiff, 1982), implying that the lobe reconnection can take place simultaneously in both hemispheres. In addition, particle distribution functions at the lobe magnetopause (Gosling et al., 1991) and the direction of accelerated flows on the dayside magnetopause (Paschmann et al., 1990; Kessel et al., 1996) confirm that 
magnetopause reconnection at the lobe boundary does indeed take place.

The key difference between this northward-IMF, lobe reconnection (at latitudes above the magnetic cusps) and southward-IMF, low-latitude reconnection (between the two magnetic cusps), is that the latter generates open flux whereas the former reconfigures flux that is already open. Lobe reconnection instantaneously changes the point where an "old" open field line threads the magnetopause from somewhere down the tail to the reconnection site. Observations show that some lowlatitude open flux generation can continue when the IMF is northward. Freeman et al. (1993) found that antisunward polar cap convection turned to sunward motion when the IMF clock angle was such that the magnitude of the clock angle $|\theta|$ was less than about $70^{\circ}$ : we here define IMF clock angle $\theta$ and elevation angle $\phi$ by:

$\theta=\left(B_{y} /\left|B_{y}\right|\right) \tan ^{-1}\left(\left|B_{y}\right| / B_{z}\right)$

$\phi=\left(B_{x} /\left|B_{x}\right|\right) \tan ^{-1}\left(\left|B_{x}\right| / B_{z}\right)$.

Scurry et al. (1994) and Phan et al. (1996) found the magnetopause flow signatures of low-latitude reconnection persisted for northward IMF provided the local magnetic shear angle did not fall below about $45^{\circ}$. A similar conclusion was reached by Fuselier et al. (1995, 1997) from electron and ion distribution functions close to the magnetopause. The exact relationship of the local magnetic shear at the magnetopause with the IMF clock angle, $\theta$, is not known but Sandholt et al. (1998) have found evidence that the dayside aurora associated with low-latitude reconnection (and which they termed "type 1") was present for $|\theta|>45^{\circ}$ whereas that associated with the lobe reconnection (which they termed "type 2") was present for $|\theta|<90^{\circ}$ and thus both were seen when $|\theta|$ was between about $45^{\circ}$ and $90^{\circ}$. Anderson et al. (1997) have proposed that the continuing low-latitude reconnection, generating open flux, when $|\theta|$ is in the range $45-90^{\circ}$ is caused by the compression of the magnetosheath field in the plasma depletion layer.

However, even though low-latitude reconnection can continue during northward IMF, we know that open flux is not generated to any great extent under these conditions. We know this because substorms are generally not observed during periods of prolonged northward IMF $\left(|\theta|<90^{\circ}\right)$ (Farrugia et al., 1993). Wygant et al. (1983) showed that the range of residual transpolar voltages during northward IMF (previously thought to be due to some unspecified "viscous-like" momentum transfer to closed field lines) dropped progressively with time since the northward turning of the IMF: this strongly indicates that such voltage is associated with open flux produced by the prior period(s) of southward IMF. Poleward contraction of the polar cap (due to closure of open flux in the tail) can mimic the dayside flow patterns expected for a viscous-like mechanism, as was postulated by Lockwood and Cowley (1992). This effect was confirmed by Fox et al. (1994), who showed examples where the apparent viscous-like voltage in- creased during polar cap contractions caused by weak substorms. Thus much of the voltage associated with antisunward flow during northward IMF is due to field line closure in the tail and is not caused by either a viscous-like interaction or field line opening at the dayside magnetopause.

Three of the important possibilities for reconnection are presented here in Fig. 1. The left hand schematics show magnetic field lines relative to noon-midnight cross sections of the magnetosphere, as viewed from dusk such that the Sun is to the left. Open, closed and interplanetary magnetic field lines are labelled $o, c$ and $i$, respectively, and open field lines reconfigured by lobe reconnection are called "over-draped lobe" (Crooker, 1992) and are labelled ol. The dashed line is the magnetopause (MP) and dots marked $\mathrm{X}$ are active reconnection sites. The right hand schematics are views of the Northern Hemisphere polar cap with the Sun to the top, dawn to the right and dusk to the left: convection flow stream lines are marked with arrows, thin solid lines are non-reconnecting segments of the open-closed boundary and thick solid lines map to magnetopause reconnection X-lines. In all cases, we show steady-state situations in the ionosphere for simplicity, but the considerations can readily be generalised for non-steady cases by allowing for the flows associated with moving boundaries (Cowley and Lockwood, 1992). The bulk of the flows shown in Fig. 1 are reconnection-driven: as discussed, the "viscously-driven" flow cells labelled $v$ are most likely to be driven predominantly by continuing tail reconnection and polar cap contraction.

The numbered field-line positions in the left hand plots show the evolution of each field line under the combined action of the magnetic curvature ("tension") force and the antisunward magnetosheath flow. The corresponding motion of the ionospheric footprint of such field lines is shown in the right hand plots. In Fig. 1a, the reconnection is between the draped interplanetary field lines in the sheath $(i)$ and closed magnetospheric field lines $(c)$. This reconnection gives poleward flow and a "standard" dispersion of cusp ions (energy decreasing with increasing latitude) as the cusp precipitation evolves with time elapsed since reconnection (Lockwood, 1995). From this discussion, we infer this type of reconnection can continue (at some local times at least) during $B_{z}>0$ when $|\theta|$ exceeds roughly $45^{\circ}$.

In Fig. 1b, lobe reconnection takes place between a draped interplanetary magnetic field, $(i)$ and the "old" open flux of the tail lobe $(o)$. Note that the old open flux was produced by a prior period of southward IMF and threads the boundary further down the tail and has a different orientation in the sheath and in interplanetary space to $i$. In this case, often referred to as "lobe stirring" (Reiff, 1982), the old open field lines like 1 evolve toward the reconnection site (to 2) before being reconfigured at $\mathrm{X}$ so that they thread the dayside magnetopause (such as 3: these reconfigured open field lines have been called "over-draped lobe" flux see Crooker, 1992). These move sunward under magnetic 

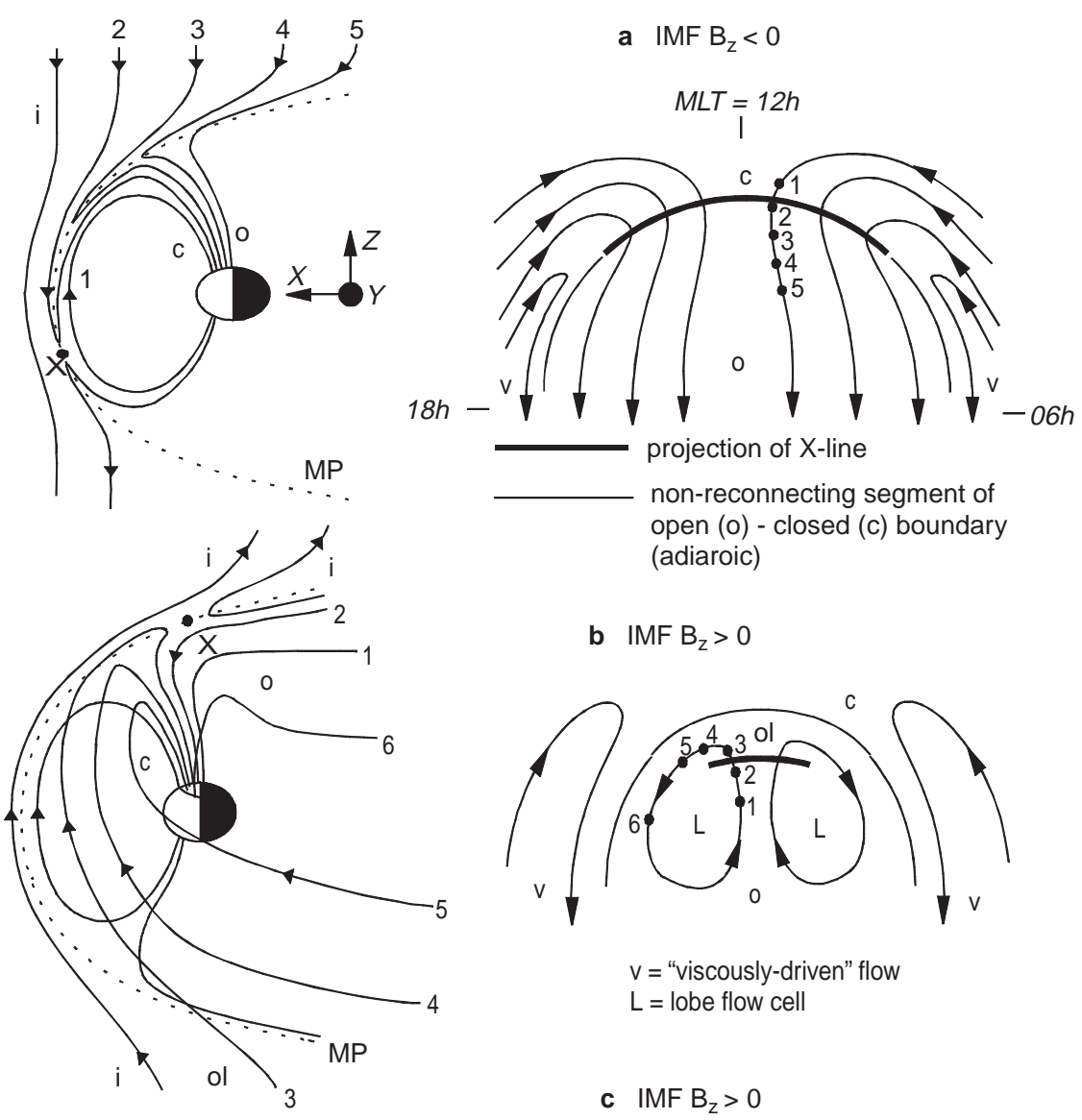

b $\quad$ IMF $B_{z}>0$

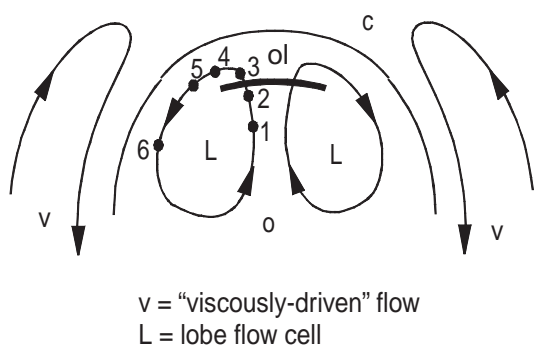

c $\quad$ IMF $B_{z}>0$

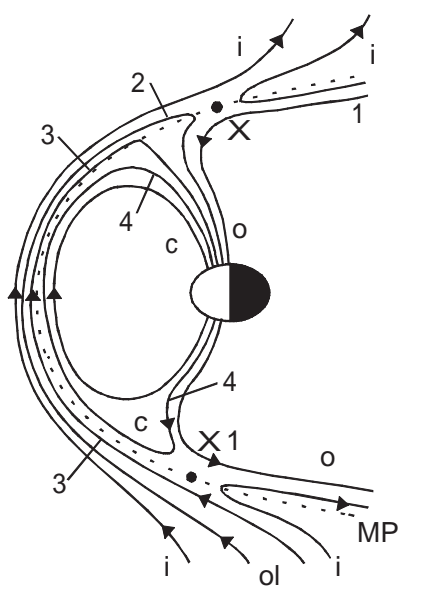

Fig. 1a-c. Schematic illustrations of (left) the evolution of reconnected field lines in the magnetosphere, as seen from the dusk flank and (right) the corresponding steady-state flow in the Northern Hemisphere ionosphere, with noon to the top. a is for southward IMF whereas $\mathbf{b}$ and $\mathbf{c}$ are two of the possibilities for northward IMF in all cases with $B_{y} \approx 0$. Field lines and regions that are open, closed, interplanetary and overdraped lobe are lobe are labelled, respectively, $o, c, i$, and $o l$. See text for details (adapted from Lockwood, 1998)

tension, before sliding around either the dawn or dusk flank and being returned to the tail lobe by the magnetosheath flow. Evolution back into the tail lobe may be slow as the magnetic curvature force is initially acting against the sheath flow. This case can, in principle, exist in steady state with lobe flux circulating around a flow cell (L) within the open field line region, as shown in the right hand schematic. However, in reality, this is unlikely to be a steady-state phenomenon and flux is very unlikely to circulate all the way around because the lifetime of the flow cells (controlled by the persistence of the IMF orientation) is shorter than the time for flux tubes to circulate around the cells. After lobe reconfiguration, the field line threads the dayside magnetopause, allowing higher density sheath plasma to stream into the magnetosphere and precipitate into the cusp ionosphere, sunward of the magnetic projection of $\mathrm{X}$ (the thick solid line). The sunward convection will give a reversed cusp ion dispersion (Woch and Lundin, 1993), as the ion precipitation evolves with elapsed time since reconnection. The precipitation seen on the old open flux, poleward of the solid line (at the foot of field lines 1 and 2) would be classed as either mantle or polar cap (as prior to the reconfiguration, the sheath plasma will flow mainly tailward on the old open field lines). Because some of the overdraped lobe field lines move 
only very slowly, due to the competing effects of the sheath flow and tension force, some of the cusp could be relatively stagnant and the precipitation relatively dispersionless. Figure 1 is drawn for small IMF $\left|B_{y}\right|$ and so the lobe convection cells are roughly equal in size whereas one of these would dominate for large $\left|B_{y}\right|$ (Russell, 1972; Heelis, 1984).

Crooker and Rich (1993) found that lobe convection cells L are predominantly a summer phenomenon which they explained as the effect of the dipole tilt towards the sun which favours lobe reconnection in the summer hemisphere. In the opposite hemisphere to the lobe reconnection site $\mathrm{X}$ (the Southern Hemisphere in Fig. 1b), the lobe reconnection has no effect (Freeman et al., 1993; Crooker and Rich, 1993; Knipp et al., 1993).

An alternative situation is shown in Fig. 1c where the overdraped lobe flux produced by X (like field line 3 ) is itself reconnected at X1 in the other hemisphere to produce a closed field line (like field line 4). This is similar to the original suggestion for $B_{z}>0$ by Dungey (1963), recently invoked by Song and Russell (1992), Song et al. (1994) as a way of producing a closed fieldline low-latitude boundary layer containing magnetosheath plasma. The example shown in Fig. 1c is the most realistic in that field lines are not simultaneously reconnected at both lobe sites. In the case shown, reconnection occurs first in the Northern Hemisphere and only subsequently does the overdraped lobe field line reconnect in the Southern Hemisphere. Note that the flow cells with sunward polar cap flow now cross between the open and closed field line regions and do not remain in the region of open flux as in Fig. 1b. If the reconnection rate at $\mathrm{X} 1$ exceeds that at $\mathrm{X}$, the Northern Hemisphere overdraped lobe flux will decay, the latitudinal width of the northern cusp would shrink. After the Northern Hemisphere ol field has disappeared at any one local time, X1 would act to expand an overdraped lobe connected to the Southern Hemisphere.

In this study, we present optical observations of the dayside cusp/cleft aurora made from Spitsbergen, one of the Svalbard islands, near the December solstice and at 9 UT. Observations of the cusp aurora are possible in the dark magnetic-noon, winter conditions at Svalbard (sun more than $10^{\circ}$ below the horizon) for, roughly speaking, a two-month observing season about the December solstice and around 9 UT, when the viewing area is close to 12 MLT. Selecting these dark conditions at noon means that we study an extreme magnetic topology in the cusp region, with the Earth's rotational axis tipped away from the Sun at an angle of $23.5^{\circ}$ at winter solstice, and with a further tip of the northern magnetic axis. At this UT, the angle of the magnetic axis (projected onto the GSE $X Z$ plane) with respect to the $Z$ axis is $\delta=28^{\circ}$. The dipole tilt would be greatest at $5 \mathrm{UT}\left(\delta \approx 35^{\circ}\right)$, when a location roughly $60^{\circ}$ to the east of Svalbard is at magnetic noon.

The dipole tilt effect on the dayside cusp precipitation (Newell and Meng, 1989) and magnetopause field topology was invoked by Crooker and Rich (1993) as the reason that the lobe reconnection cells are seen predominantly in the summer hemisphere. In the winter hemisphere, a large $B_{x}$ component of the IMF would be required to drape a northward-pointing IMF such that it produced an anti-parallel field configuration on the lobe boundary, whereas such a configuration is much more readily achieved in the summer hemisphere. Thus the IMF $B_{x}$ component is likely to be of relevance as it should favour lobe reconnection in one hemisphere $\left(B_{x}<0, B_{z}>0\right.$ should favour the Northern Hemisphere, whereas $B_{x}>0, B_{z}>0$ should favour the Southern Hemisphere).

Figure 2 illustrates how the IMF $B_{x}$ effect on lobe reconnection can be characterised by the elevation angle of the IMF $\phi$ (as defined by Eq. 2). Figure 2 shows selected geomagnetic field lines predicted by the Tsyganenko T96-01 model at 11 UT at equinox $(\delta=0)$ and 9 UT at December solstice $\left(\delta=28^{\circ}\right)$. At the equinoxes, $0<\phi<90^{\circ}$ would be an IMF orientation that favoured Southern Hemisphere lobe reconnection (at the site LX in Fig. 2a) whereas the range $\left(-90^{\circ}\right)<\phi<$ 0 would favour northern lobe reconnection (Fig. 2b). However, for the observations discussed here at 9 UT and near December solstice, the dipole axis is tipped at $\delta=28^{\circ}$ and Fig. 2c shows how we would expect the southern lobe to be favoured for most values of $\phi$ (roughly speaking for the range $-\delta<\phi<90^{\circ}$ ). For Northern Hemisphere lobe reconnection to occur would require $-90^{\circ}<\phi<-\delta$ and so calls for $\phi$ to be close to $\left(-90^{\circ}\right)$ (Fig. 2d).

In this work, we first present observations of changes in the interplanetary medium, made by the WIND satellite, and contrast with observations of the response of the dayside cusp/cleft aurora, as detected by meridian-scanning photometers at Ny Ålesund, Svalbard and an all-sky camera at Longyearbyen, Svalbard. In the subsequent section, we interpret the optical observations in terms of the appearance and disappearance of different reconnection sites and relate these to the changes in the IMF orientation. These observations were made during northward IMF near winter solstice when the dipole axis is tipped at $\delta=28^{\circ}$. Hence lobe reconnection should be favoured in the Southern Hemisphere for most values of the IMF elevation angle. However, we argue that for sufficient magnitude of negative IMF $B_{x}$ values, lobe reconnection should occur in the Northern Hemisphere (Fig. 2).

\section{Observations}

\section{IMF and solar wind observations}

Figure 3 shows observations of the IMF components, in GSM coordinates, made by the WIND satellite on 12 January 1997, between 07:30 and 09:00 UT. At this time the satellite was located near $\left(X=103 R_{\mathrm{E}}\right.$, $Y=-55 R_{\mathrm{E}}$, and $\left.Z=-6 R_{\mathrm{E}}\right)$ in GSM co-ordinates. The solar wind speed in this interval was approximately constant at $530 \mathrm{~km} \mathrm{~s}^{-1}$. From this we estimate that the propagation delay from the satellite to the magnetopause is $23 \pm 3 \mathrm{~min}$. This estimate includes a propagation time of $17 \mathrm{~min}$ from WIND to a bow shock at 
a $\quad 0<\phi<\pi / 2$

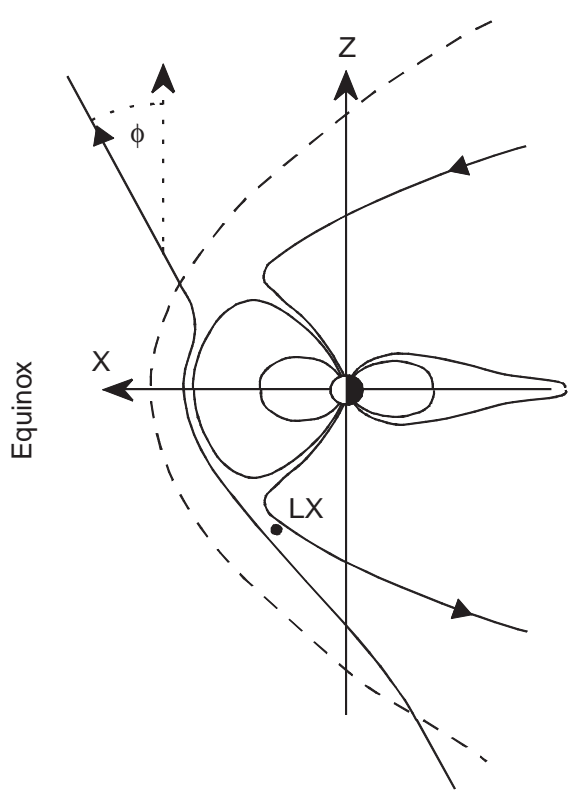

c $\quad-\delta \leqslant \phi<\pi / 2$

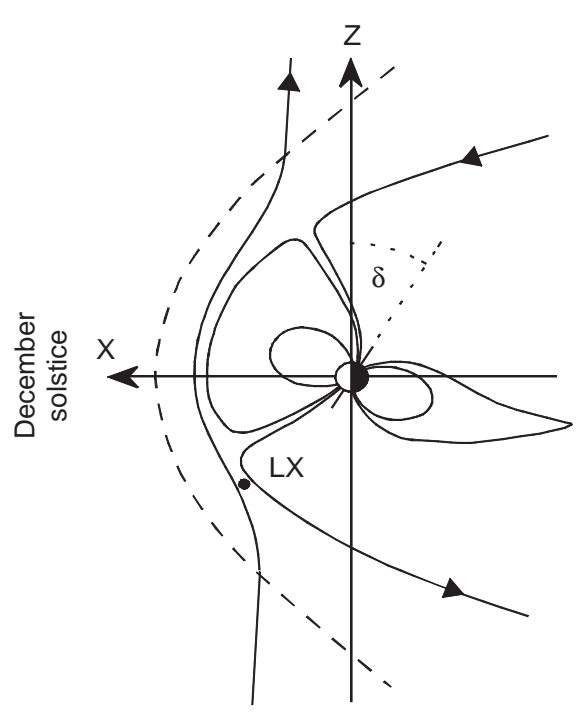

b $0>\phi>-\pi / 2$

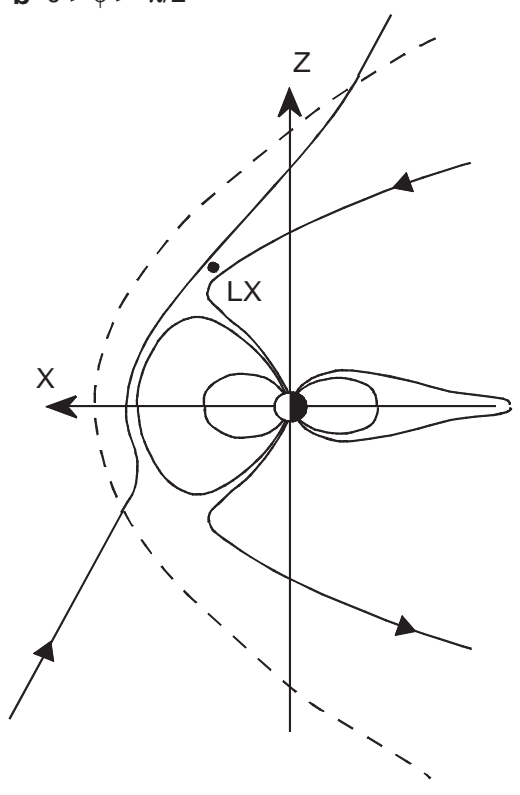

d $\quad-\pi / 2<\phi \lesssim-\delta$

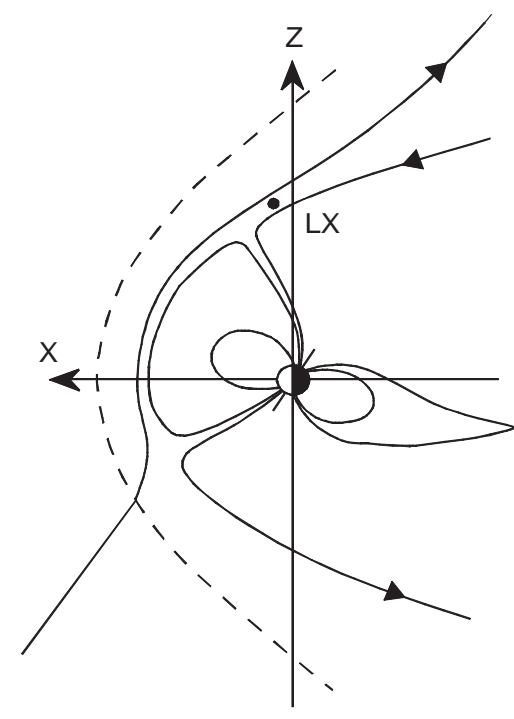

Fig. 2a-d. Schematic illustration of lobe reconnection for equinox (a and $\mathbf{b}$ ) and December solstice (c and d) conditions with various IMF elevation angles $\phi$. In a $B_{x}>0$, $B_{z}>0\left(0<\phi<90^{\circ}\right)$ and this should favour a lobe reconnection site (LX) in the Southern Hemisphere. In the other 3 cases, $B_{x}<0, B_{z}>0\left(-90^{\circ}<\phi<0\right)$. At equinox, this favours the Northern Hemisphere if (as in b), but at December solstice would favour the Southern Hemisphere if $\phi>-\delta$ (as in $\mathbf{c}$ ), where $\delta$ is the tilt of the Earth's dipole axis with respect to the $Z$ axis in the $X Z$ plane: northern lobe reconnection would require $\phi$ to be close to $-90^{\circ}$ (as in d)
$X=15 R_{\mathrm{E}}$, plus a time of $6 \mathrm{~min}$ to cross the magnetosheath. The uncertainty is derived from the fact that the orientation of the changes in the interplanetary medium is not known and we use the observed fluctuation level of the IMF longitudinal angle of $\pm 15^{\circ}$ to estimate the lag uncertainty. To this we add a further 2 min to allow for the minimum electron flight times from the magnetopause to the ionosphere and the average radiative lifetime of the $630 \mathrm{~nm}$ atomic oxygen emission line. Thus we deduce an average delay of about $25 \pm 3$ min between the observation of an IMF or solar wind change by WIND and the associated change seen in the $630 \mathrm{~nm}$ cusp/cleft aurora. Notice, however, that high flux precipitation can persist for several tens of minutes down open field lines following reconnection: hence the delay may be as much as $35 \mathrm{~min}$ between an IMF change that causes a cessation of reconnection and the conclusion of the consequent fading of an auroral structure.

The solar wind density, like the solar wind speed, was relatively steady. It fluctuated in the range $7-8.5 \mathrm{~cm}^{-3}$ in the interval 07:30-09:00. Important changes, however, did take place in the IMF. The $B_{z}$ component increases from southward to northward in a relatively smooth manner, giving a gradual fall in the IMF clock angle, but with a discontinuous change through $B_{z}=0$ at $08: 23$. There is a brief return to a southward orientation lasting 2 min around 08:44 UT. At 08:00 the $B_{y}$ component is negative $(-1.5 \mathrm{nT})$, but this turns positive shortly thereafter and increases to about $+5 \mathrm{nT}$ before declining again. The $B x$ component is negative after 08:00 but fluctuates between $-4 \mathrm{nT}$ and $-2 \mathrm{nT}$. The elevation angle of the IMF $\phi$ (bottom panel of Fig. 3) is initially close to $-180^{\circ}$, but increases through $-90^{\circ}$ with 


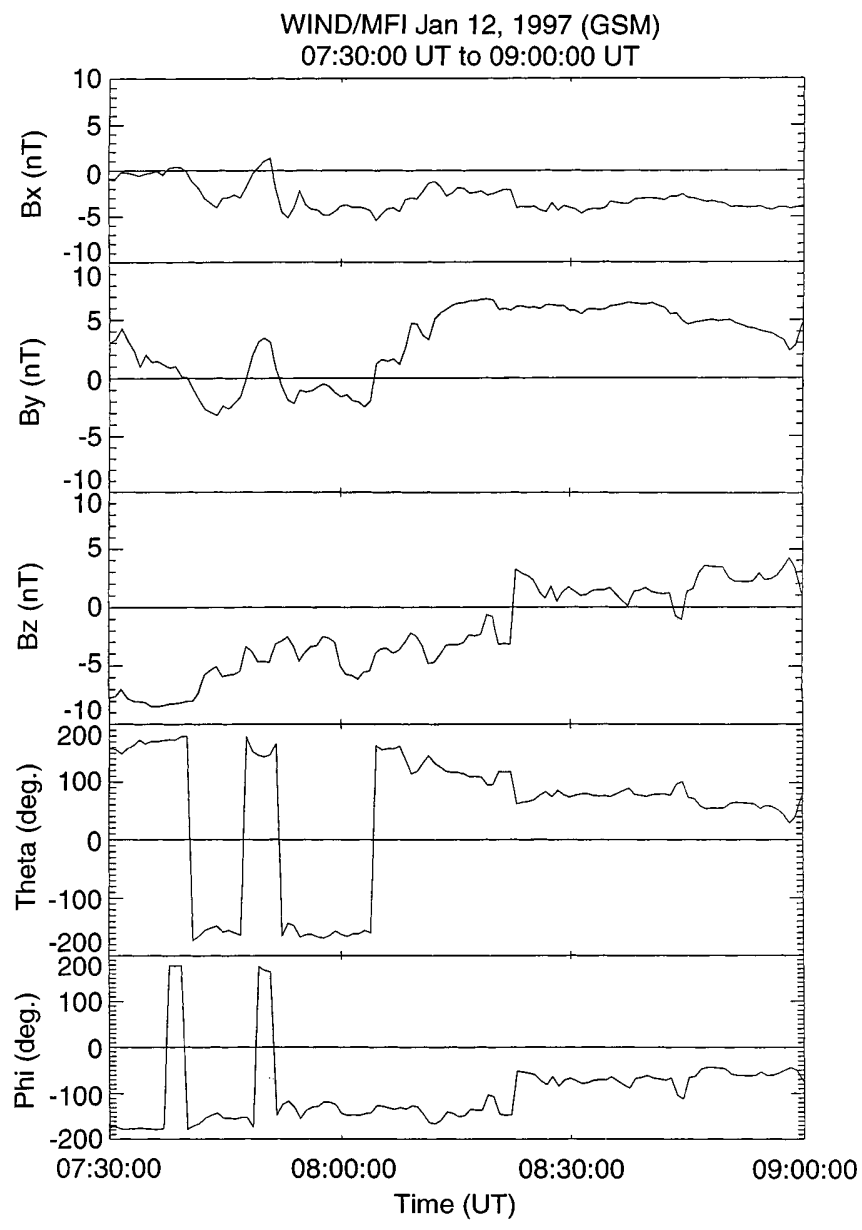

Fig. 3. IMF observations by the WIND satellite on 12 January 1997, between 07:30 and 09:00 UT. The estimated satellite-to-ionospheric cusp propagation delay is about $25 \mathrm{~min}$. The panels show (from top to bottom) the $B_{x}, B_{y}$ and $B_{z}$ IMF components (in the GSM frame and in nT), the clock angle $\theta$, defined by Eq. (1), and the elevation angle $\phi$, defined by Eq. (2) (both in degrees)

the northward turning at 08:23 UT. Subsequently $\phi$ remains between $-70^{\circ}$ and $-90^{\circ}$ until the brief excursion to $B_{z}<0$ at 08:44. After $08: 45 \phi$ is between $-40^{\circ}$ and $-60^{\circ}$. For the time of the observations, $\delta=28^{\circ}$ therefore prior to $08: 44 \mathrm{UT}, \phi$ is significantly smaller than $\left(-\delta\right.$ ) (by over $40^{\circ}$ ) whereas after 08:45 $\phi$ is within $30^{\circ}$ of $(-\delta)$. During this time, the clock angle $\theta$ decreases gradually from near $180^{\circ}$ at $08: 00$, falling below $45^{\circ}$ only briefly near the very end of the interval (08:58). Figure 4 shows the behaviour of the IMF in this interval in the form of two hodograms: the three dots are for 08:00, 08:30 and 09:00. In both the XZ and YZ GSM planes, the field shows the systematic changes described already. It is the aim of this work to study the effects of these field rotations on the dayside cusp auroral, as seen in $630 \mathrm{~nm}$ light at magnetic noon.

\section{Photometer observations}

Figure 5 shows the intensity of $630 \mathrm{~nm}$ (left) and $557.7 \mathrm{~nm}$ (right) auroral emissions seen by the meridi-
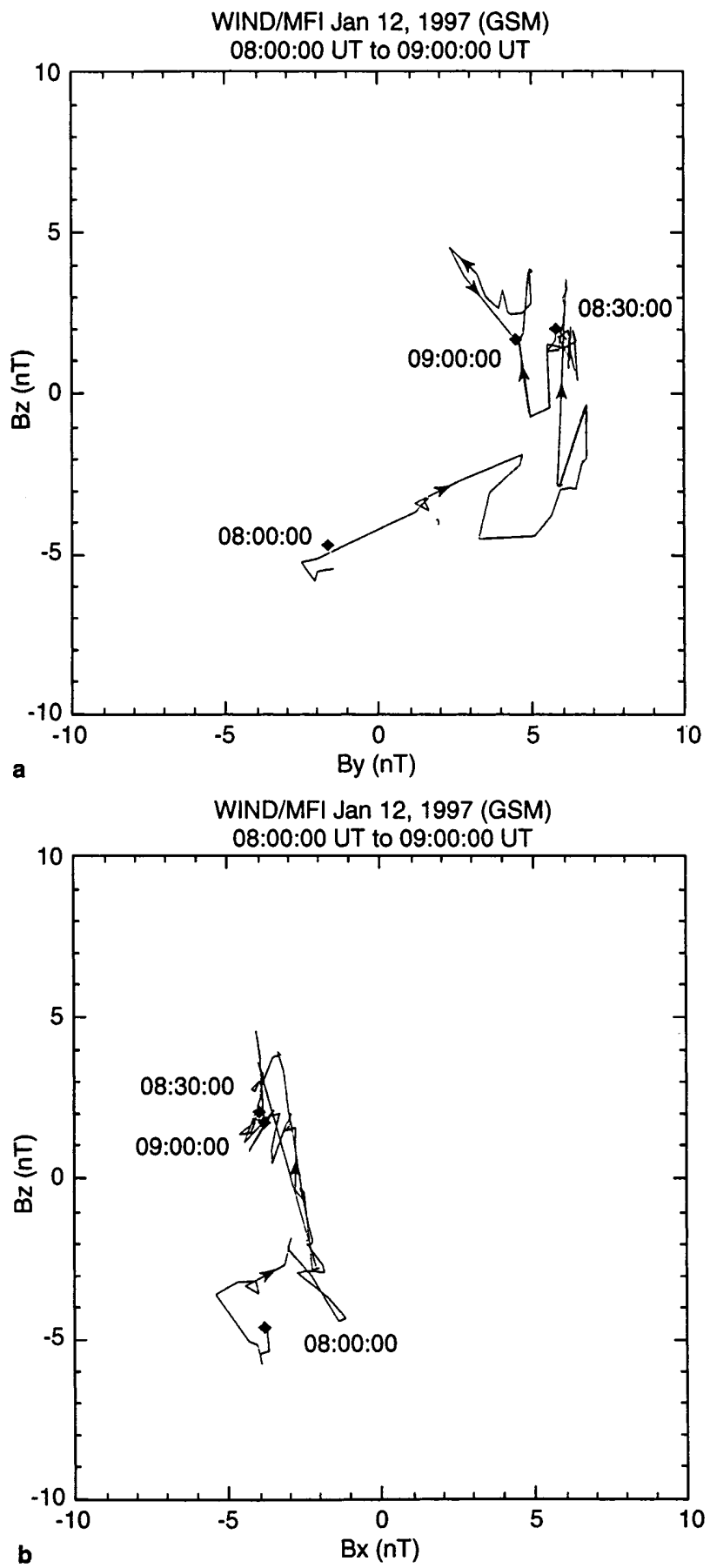

Fig. 4a, b. IMF orientations illustrated by hodograms in the a $Y Z$ and b $X Z$ GSM planes for the interval 08-09 UT. The dots are for 08:00, 08:30 and 09:00

an-scanning photometer at Ny Ålesund, Svalbard. This instrument is situated at $78.9^{\circ} \mathrm{N}$ and $11.9^{\circ} \mathrm{E}$, and is at a magnetic latitude of $75.9^{\circ}$. In both panels, time runs from 08:30 UT at the top to 09:32 UT at the bottom and the intensity is shown as a function of zenith angle (with $80^{\circ}$ to the north to the left and $75^{\circ}$ south to the right) along the magnetic meridian for each UT. The latitudes corresponding to these zenith angles depend on the emission altitude, as given by Lockwood et al. (1993). The MLT of the observing site increases from 


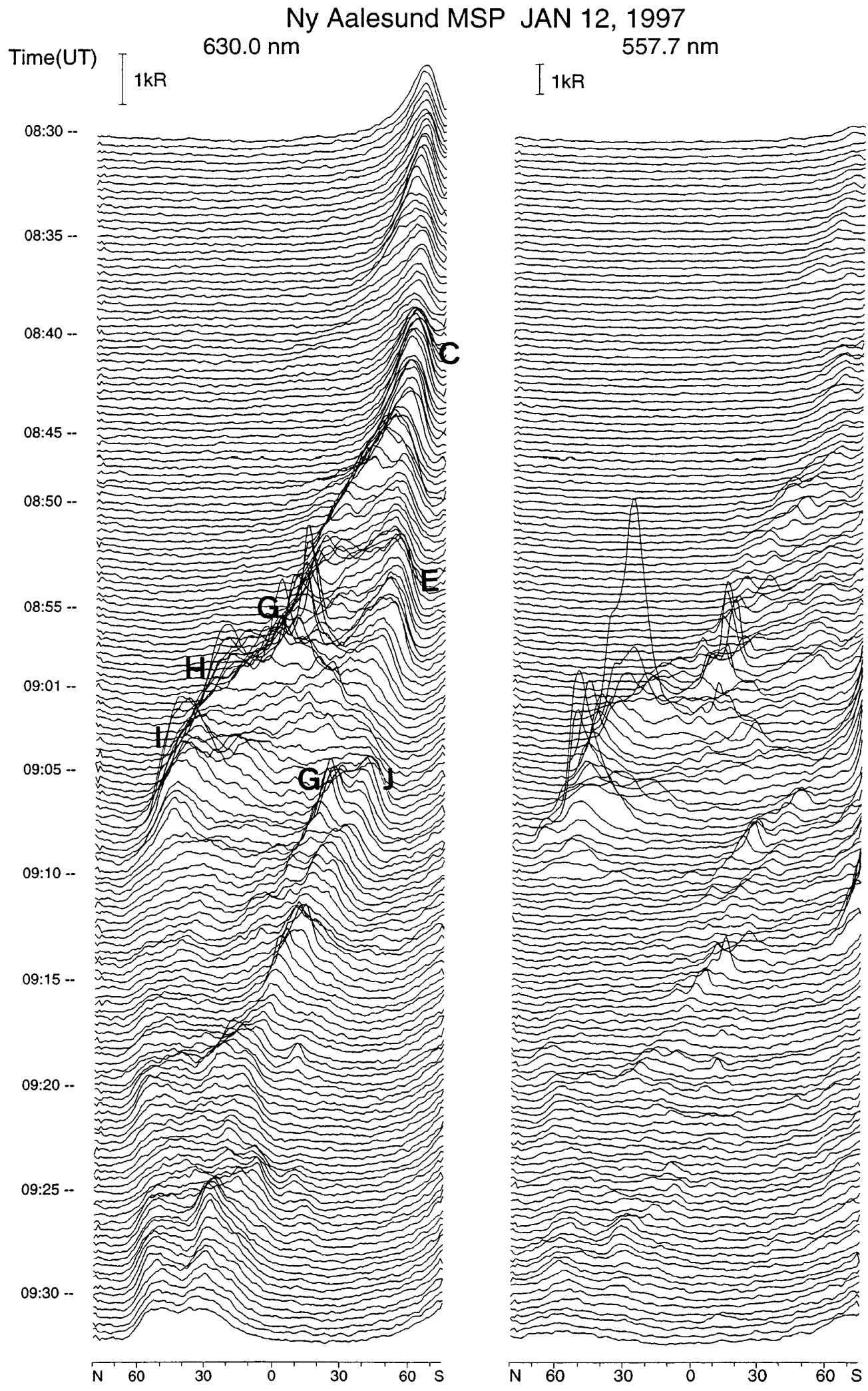

Fig. 5. Scans by the meridianscanning photometers at $\mathrm{Ny}$ Ålesund, Svalbard on 12 January 1997. $630 \mathrm{~nm}$ (left) and $557.7 \mathrm{~nm}($ right $)$ intensity is shown as a function of time (increasing down the page) and zenith angle according to the scale bars given at the top of each column. The zenith angles vary between $80^{\circ}$ to the north of Ny Alesund and $70^{\circ}$ to the south. The latitude of the emissions depends on the emission profile with altitude (see Lockwood et al., 1993). Auroral forms seen by the $630 \mathrm{~nm}$ all-sky camera, are marked for the on left panel if and when they appear in the merdian scanned by the photometer, using the same lettering code as Fig. 6

about 11:15 to $12: 15$ in this interval, so the observations are made close to magnetic noon. At the start of the interval, the aurora was relatively weak and unstructured and peaked at about $63^{\circ}$ south of zenith. This corresponds to a magnetic latitude near $74^{\circ}$, consistent with the lagged IMF having been predominantly southward (average $B_{z} \approx-5 \mathrm{nT}$ ) since about 06:15 UT. A weak intensification, followed by a poleward-moving event, was seen commencing about 08:32. At 08:40 there was an intensification (labelled C), after which a second band of aurora broke away from the poleward edge and moved poleward. We here adopt the terminology 
introduced by Sandholt et al. (1996) and call the new more poleward band "type 2" and the more equatorward band "type 1". The type 1 persisted and intensified around 08:55 (E). Shortly after this time, a strong, new auroral form $G$ was seen in the higher-latitude, type 2 band in both $630 \mathrm{~nm}$ and $557.7 \mathrm{~nm}$ light (this is confirmed to have been a new event by the all-sky camera data, see next section) and moved equatorward. As this faded, the type 1 moved poleward and brightened intermittently in both the red and the green light (J). The type 2 aurora brightened twice more (H and I) and then persisted at a lower intensity at a constant latitude. By the end of the period the two emission bands had almost merged into one band of $630-\mathrm{nm}$ dominant emission, well to the north of the observing site (type 1 only). This major poleward motion of the 630-nm noon aurora appears to have been the response to the northward rotation of the IMF shown in Figs. 3 and 4 . In addition to this evolution over about $45 \mathrm{~min}$, there are changes which may be associated with shorterlived IMF variations. For example, the IMF returned briefly southward near 08:44 (Fig. 3) and this may have caused of the decay of the type 2 band and the intensification of the type 1 at around 09:08 UT. Auroral forms that were also seen in the all-sky camera data (see next section) are labelled in Fig. 5: C, E, and $\mathbf{J}$ are part of the type 1 aurora, whereas $\mathrm{H}$ and $\mathrm{I}$ are intensifications of the type 2 aurora. The camera data reveal that these are two out of 5 events that form at the poleward edge of the type 2 aurora and migrate equatorward to join the type 1 aurora before fading. This motion takes place to the west of the scanned meridian and is not seen by the photometer, except for event $G$ that just extends sufficiently far eastward to touch the meridian. This event is brightest shortly after it forms (at 08:58) in the type 1 band and just before it fades (at 09:12) near the type 2 band: between these two times the event is much less intense at the meridian, but its equatorward motion can still be discerned in Fig. 5. Equatorward-moving type 2 transient auroral events during northward IMF were first reported by Sandholt (1991).

The right-hand panel of Fig. 5 shows that many of the features seen in the $630-\mathrm{nm}$ emissions are seen in the $557.7-\mathrm{nm}$ emissions also. In general, the $630 \mathrm{~nm}$ emissions are more intense, consistent with soft cusp/cleft electron precipitation. However, some events show enhanced 557.7 emission, particularly the events $\mathrm{G}, \mathrm{H}$ and I when they first form at the poleward boundary of the type 2 aurora.

\section{All-sky camera observations}

Figure 6 shows selected 1-s all-sky images recorded during this auroral sequence, as seen by the $630 \mathrm{~nm}$ allsky camera at Longyearbyen, $120 \mathrm{~km}\left(1^{\circ}\right.$ of magnetic latitude) to the south of Ny Ålesund along the magnetic meridian. The line-of-sight intensities have been mapped onto a geographic grid by assuming a constant and single emission altitude of $250 \mathrm{~km}$. Note that the intensities seen in the bottom right of each plot are the effect of scattered sunlight within the field-of-view (f.o.v.). In the first image, frame1 (for 08:33:14 UT), the aurora form a weak and thin band at almost constant L values, well to the south of Svalbard. The most intense aurora in this band is to the west of the magnetic meridian scanned by the Ny Alesund. This auroral form is labelled A in Fig. 6. In image 2, for 08:49:38 ( 16 min later), four major changes have taken place: (a) the bright patch A to the west has faded, but the low-latitude band can still be seen, (b) a second band B has appeared to the west at higher latitudes, having emerged from the poleward edge of the pre-existing band; (c) a major intensification $\mathrm{C}$ is seen to the east (inspection of the images between images 1 and 2 shows that this has spread along the pre-existing band from the east); and (d) there has been a poleward-moving transient event $\mathrm{D}$ which also expanded into the f.o.v. from the east and is now fading at higher latitudes to the east.

In image 3 (08:58:40 UT, $522 \mathrm{~s}$ later), the high luminosity to the east, $C$, has retreated eastward somewhat and the poleward, type 2, aurora B has moved slightly equatorward. There is a brief equatorward expansion of the aurora with (rayed) activity on the lower band to the south of Spitsbergen (E) and a pair of intensifications have recently commenced on the higher latitude band very close to Ny Ålesund (forms F and $G$ which appeared at 08:56 and 08:58). The second of these is the first of the events to be seen at the longitude of the photometer scan (giving the event labelled $\mathrm{G}$ in Fig. 5).

In image 4 (09:03:21 UT, $281 \mathrm{~s}$ later), all activity on the equatorward band has ceased to the west of Spitsbergen but the feature B has faded and moved a considerable distance equatorward to just poleward of where the low-latitude band used to be. The features $\mathrm{F}$ and $G$ have expanded by spreading to the north and to the west. Just to the east of $G$, a new feature $H$ is seen forming.

In image 5 (09:05:41 UT, $140 \mathrm{~s}$ later) the events $\mathrm{F}$ and $G$ have continued to move west, but have also moved increasingly equatorward. The faint remnants of the original type 2 feature, B, can still just be seen as a very weak patch at the equatorward edge of the western end of the visible auroral band. The feature to the north of Svalbard, $\mathrm{H}$ has intensified and a new event I has formed to the east of it. The south-west motion of events F, G, H and I continues in images 6 (09:07:02, $81 \mathrm{~s}$ later) and 7 (09:08:22, a further $80 \mathrm{~s}$ later).

In image 6 , form $F$ brightens considerably and the form $\mathrm{G}$ is approaching it at its eastern end. This merging is almost complete in image 7 , and thus the equatorward edge of the aurora to the west of Svalbard is made up of forms $F$ and $G$, which initially formed at the poleward edge of the type 2 aurora. In addition, a small form $\mathbf{J}$ has suddenly brightened just equatorward of $\mathrm{G}$. This feature crosses the photometer meridian and so can also be seen in Fig. 5. It drifts poleward over the next 15 min.

Image 8 (09:14:23 UT, 6 min later) shows that the patch $\mathrm{C}$ to the east has finally faded away. By this time, 

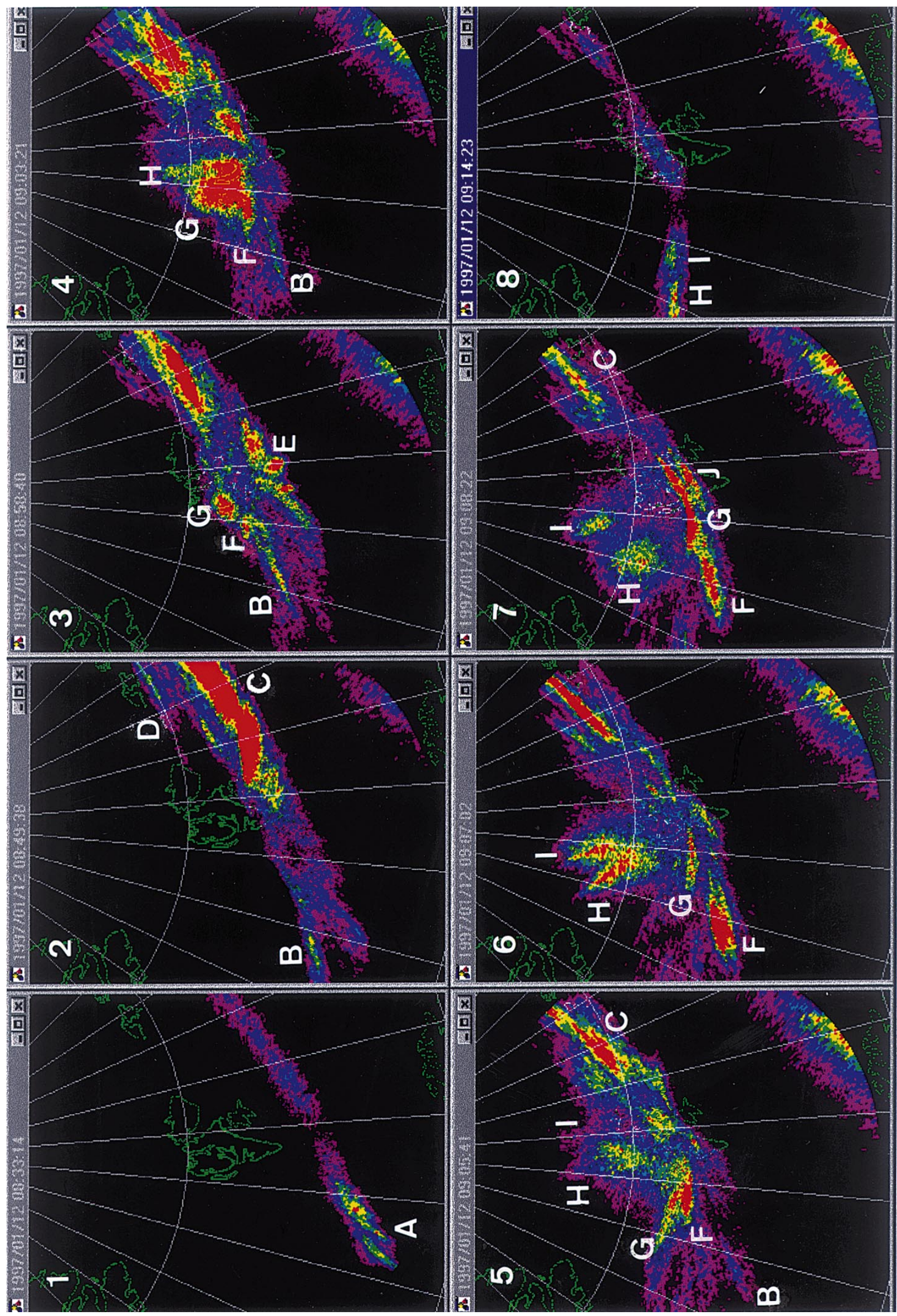
Fig. 6. A series of all-sky images by the $630 \mathrm{~nm}$ camera at Longyearbyen, Svalbard on 17 January 1997: (1) 08:33:14 UT; (2) 08:49:38; (3) 08:58:40; (4) 09:03:21; (5) 09:05:41; (6) 09:07:02; (7) 09:08:22; and (8) 09:14:23. Various auroral forms (including both long-lived structures and transient events) are labelled $A-I$

the 630 -nm aurora forms a weak single band at latitudes to the north of $\mathrm{Ny}$ Alesund, with slightly stronger intensities seen to the far west of the field of view. This enhanced emission is the remnants of the last two of the southwestward moving events, $\mathrm{H}$ and $\mathrm{I}$.

Thus the images show that there was a great deal of structure and equatorward motion, which was not generally seen by the photometer. In addition, they reveal the westward motion of the auroral forms. A key point to note that is the type 2 structure which forms to the north of the pre-existing (southward IMF, type 1) auroral band develops into a series of events. Their elongated nature almost certainly reflects a rayed-arc structure. In considering their true motion we must remember the viewing geometry and that the emission comes from a range of altitudes. They appear to rotate around the observation site only because they are moving south-westward and to the north west of the camera. The sequence of images 3, 4, 5 and 6 are chosen to be close together in time to show that this poleward activity develops into a series of events that drift west and to the south and always end by moving into the equatorward edge of the lower latitude auroral band to the west of Svalbard and fading. The first event to do this, B, was first seen at around 08:49 UT (when it formed the new poleward auroral band to the west of Svalbard) and it disappeared (after fading and brightening again during its south westward motion) into the equatorward auroral edge at 09:06, giving it a total lifetime of $17 \mathrm{~min}$. The second event to follow this sequence (F) formed at about 08:56 and faded at 09:11 so it had a shorter lifetime of $15 \mathrm{~min}$. Event $\mathrm{G}$ formed at 08:58 and faded at 09:12, giving it a lifetime of $14 \mathrm{~min}$. Event $\mathrm{H}$ formed at about 09:03 and faded at 09:15, making its lifetime $12 \mathrm{~min}$ and event I formed at 09:05 and also faded at 09:15, so its lifetime was $10 \mathrm{~min}$.

Thus there is a sequence of five of these events, which form at the poleward edge of the type 2 aurora and migrate south and west before fading at the equatorward edge of the type 1 aurora. Their formation times are separated by 7,2,5 and 2 min and their lifetime gets progressively shorter from 16 to $10 \mathrm{~min}$. They form only in the interval 08:49-09:05 UT.

\section{Interpretation of the images}

The auroral intensities are, at most times, dominated by the $630 \mathrm{~nm}$ emission, the relatively low emission of $557.7 \mathrm{~nm}$ light showing that most of the emission is caused by soft magnetosheath-like particles. The exceptions to this are all short-lived and associated with the onset of the equatorward-moving events in the type 2 aurora. Lockwood et al. (1993) found that dominant
$557.7 \mathrm{~nm}$ emissions in transient events were in the regions of upward field-aligned current associated with the flows.

The orientation of the IMF is known to vary during the interval and so the location of magnetopause reconnection sites is expected to move, whether one envisages anti-parallel merging (Crooker, 1979) or tilted subsolar reconnection during southward IMF, giving way to lobe reconnection during northward IMF (e.g. Gosling et al., 1990, 1991). Furthermore, the variation of the soft-electron precipitation seen subsequent to each reconnection, will depend on how the opened field lines evolve over the magnetopause (Onsager et al., 1993; Lockwood, 1995) and this too will depend critically on the IMF orientation. In addition, the magnetic mapping of the reconnection site to the ionosphere is altered by the penetration of IMF components (particularly $B_{y}$ ) into the magnetosphere (Cowley et al., 1991).

One clear effect observed in Figs. 5 and 6 is the poleward motion of the cusp/cleft aurora in response to the northward turning of the IMF. This is expected from statistical studies of the latitude of cusp precipitation (e.g. Burch, 1973; Candidi et al., 1983; Newell et al., 1989) and from studies of the dayside cusp/cleft aurora (Horwitz and Akasofu, 1977; Sandholt et al., 1998). These figures also show, however, that the cusp/cleft aurora is narrow in latitudinal width when the IMF was both strongly southward and strongly northward. This is somewhat surprising as statistical studies have suggested the cusp and cusp/cleft regions are much wider in latitude under northward IMF conditions (Carbary and Meng, 1988; Newell and Meng, 1987). The precipitation seen here does initially spread in latitude following the northward turning, but then decreases again in latitudinal width. This is particularly apparent in the photometer data shown in Fig. 5. We therefore conclude that cusp latitudinal width is not a simple function of IMF $B_{z}$ but also depends on other factors.

The formation of type 2 events and structures poleward of the original type 1 aurora indicates that lobe reconnection has set in the Northern Hemisphere lobe (Weiss et al., 1995; Sandholt et al., 1996, 1998a, b; Øieroset et al., 1997). These features initially form at the poleward edge of the pre-existing type 1 aurora, as noted by Øieroset et al. (1997). It is somewhat surprising that such features can be seen, considering that this is not favoured at this time near winter solstice because of the Earth's dipole tilt away from the sun in the Northern Hemisphere. It has been suggested that the dipole tilt causes lobe reconnection (and associated sunward flow) to be seen only in the summer hemisphere (Crooker and Rich, 1993). However in this case, the strongly negative $B_{x}$ component of the IMF could have overcome this dipole tilt effect when $B_{z}$ is only weakly positive, giving $\phi$ close to $-90^{\circ}$ and draping magnetosheath field lines over the Northern Hemisphere lobe (as in Fig. 2d). The IMF seen by WIND had such an orientation for an interval of roughly $08: 26-08: 42$, which could therefore have been responsible for the formation of the type 2 auroral events at 08:51-09:07 if the propagation delay 
from the satellite to the ionosphere was the nominal $25 \mathrm{~min}$. This was the period in which type 2 events were seen to form. It is also the period in which the poleward part of the aurora migrates poleward in Fig. 5.

Two factors then become of particular interest. Firstly, the type 2 auroral events were seen to drift equatorward into the equatorward boundary of the persistent type 1 aurora, where they faded. This suggests that the open field lines that were reconfigured by lobe reconnection may have subsequently been re-closed by reconnection in the other lobe. This has been proposed by Song and Russell (1992) and Song et al. (1994) as a way of populating a closed low-latitude boundary layer with magnetosheath plasma during northward IMF. Secondly, the nature of the poleward retreat of the type 1 (low-latitude) aurora after 09:07 is significant because it was not accompanied by a poleward motion of the more northerly type-2 aurora and so represents a narrowing of the latitudinal width of the total band of $630 \mathrm{~nm}$ aurora (as seen in Fig. 5). This narrowing also implies that re-configured lobe flux in the Northern Hemisphere was being closed by lobe reconnection in the Southern Hemisphere. Lastly, one should consider how the poleward motion of a dayside aurora can occur. In general it represents the closure of open flux. That closure could be taking place in the tail giving a polar cap contraction as discussed by Lockwood et al. (1990) and Cowley and Lockwood (1992). However, were this to have been occurring here, we would expect all of the dayside aurora (both type 1 and type 2) to have both migrated poleward, and Fig. 5 shows that this was clearly not the case in this example. Thus this strongly implies that in this case we were observing the re-closure of open flux on the dayside by lobe reconnection, such that the equatorward type 1 aurora migrates poleward, but the poleward type 2 aurora does not.

This interpretation is consistent with the observed IMF orientation changes seen by WIND. After 08:35, The $B_{x}$ component remained roughly constant but the average $B_{z}$ component increased from about $+2 \mathrm{nT}$ at 08:40 to about $+4 \mathrm{nT}$ at 09:00, corresponding to a change in the IMF orientation in the GSM $X$ - $Z$ plane from about $80^{\circ}$ to $40^{\circ}$ with respect to the $Z$ direction (last panel, Fig. 3). Given that the tilt of the magnetic dipole at this time, $\delta$ was close to $28^{\circ}$ in this frame. This rotation may have been sufficient to cause the reconnection in the northern (winter) lobe to slow and possibly cease and to have caused that in the southern (summer) lobe to commence and become dominant. The rotation of the IMF will not directly change the orientation of the interplanetary part of overdraped lobe (ol) flux; however, the accumulation of draped IMF over the overdraped lobe flux in the magnetosheath will compress it onto the Southern Hemisphere lobe and so promote its reconnection. This argument is illustrated graphically in the next section. Using the satellite-tomagnetopause delay of $25 \mathrm{~min}$. discussed above, these changes would be seen over the interval 09:05-09:25 which, as shown by the photometer data (Fig. 5), is indeed the interval in which the activity on the poleward part of the oval decays and in which the equatorward type 1 aurora migrates poleward. Note that the migration proceeds most rapidly after each of a series of intensifications of this auroral band suggesting that the Southern Hemisphere lobe reconnection closing the overdraped lobe also occurs in bursts.

We note also that the appearance of the small feature $\mathbf{J}$ and the fading of the type 2 aurora follow the short excursion to southward IMF around 08:44 by the predicted lag. We suggest that event $\mathbf{J}$ is similar to event $\mathrm{E}$ and that this brief swing was sufficient to cause a brief burst of low-latitude reconnection whilst marking the end of the lobe reconnection in the Northern Hemisphere (which never returned because of the drift in the IMF elevation angle $\phi$ to lower values).

\section{Schematic illustration of the proposed interpretation}

Figure 7 is a series of schematic illustrations to indicate the likely changes in the reconnection topology and how they are reflected in the dayside aurora seen at Longyearbyen. In this figure, the left-hand plots are views of the magnetosphere from the dusk side of the Earth, the middle plots are views of the magnetosphere from the sun and the right-hand plots are views of the noon polar ionosphere from above. In the left-hand plots, the magnetopause is shown as a dotted line and a segment of an active reconnection X-line as a dot. In the middle plots, lobe field lines have been omitted to avoid complicating the diagram and active reconnection $\mathrm{X}$-lines are shown as heavy lines. In the right hand plots, the circle is the field of view of the all-sky camera (the centre of which moves from 11:30 MLT to 12:30 MLT during the period of interest), flow stream lines are arrows, the thin solid segments are non-reconnecting segments of the open-closed boundary and the heavy solid lines are merging gaps which map to active reconnection sites on the magnetopause. The IMF orientations are taken from the WIND data for the nominal lag of $25 \mathrm{~min}$. The motion of boundaries and the positions of the reconnection sites are inferred from locations of the 630-nm aurora. The directions of convective flow are inferred from the orientation of the precipitation plumes in the case of quasi-steady reconnection, and from the direction of event motion in the case of transient events. In addition, dominant 557.7-nm emission is taken to show regions of upward field-aligned current.

Figure $7 \mathrm{a}$ corresponds to the start of the interval of auroral data (08:25 UT). For the inferred WIND to ionosphere lag of about $25 \mathrm{~min}$, this IMF impinging on the magnetosphere at this time would be that seen by WIND near 08:00 and have $B_{z}<0, B_{y}<0$ and $B_{x}<0$ and the orientation shown in the left and centre plots of Fig. 7a. This allows "low-latitude" reconnection (by which we here mean reconnection of closed field lines anywhere between the magnetic cusps which generates open flux) and because of the IMF orientation in the $X Y$ plane is at $90^{\circ}$ to the garden hose direction we suggest reconnection is favoured on the dawn flank of the magnetosphere. This is reflected in the location of 
a

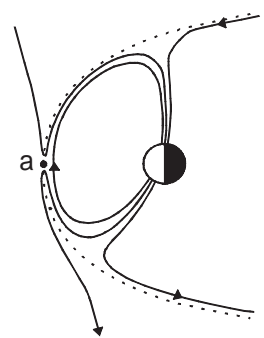

b
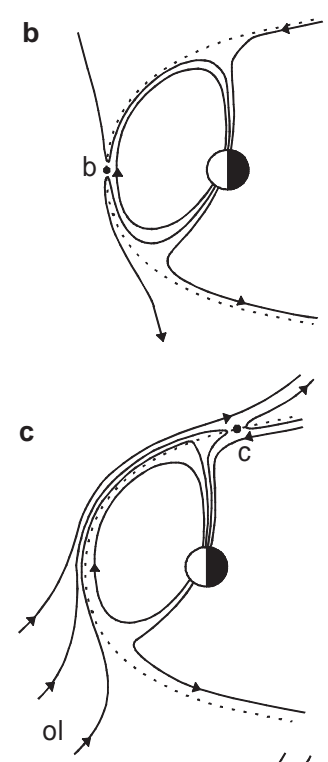

d
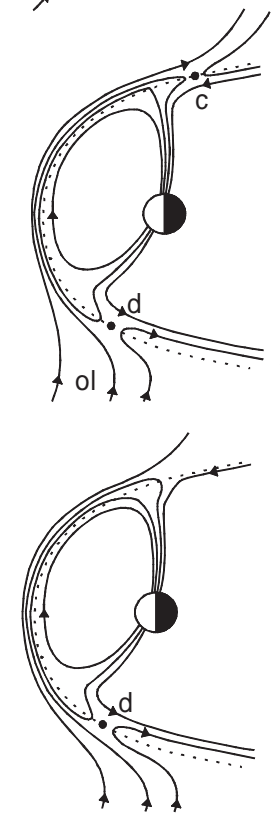

$\mathbf{f}$

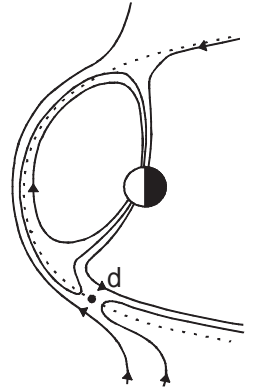

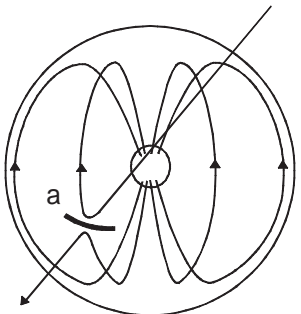
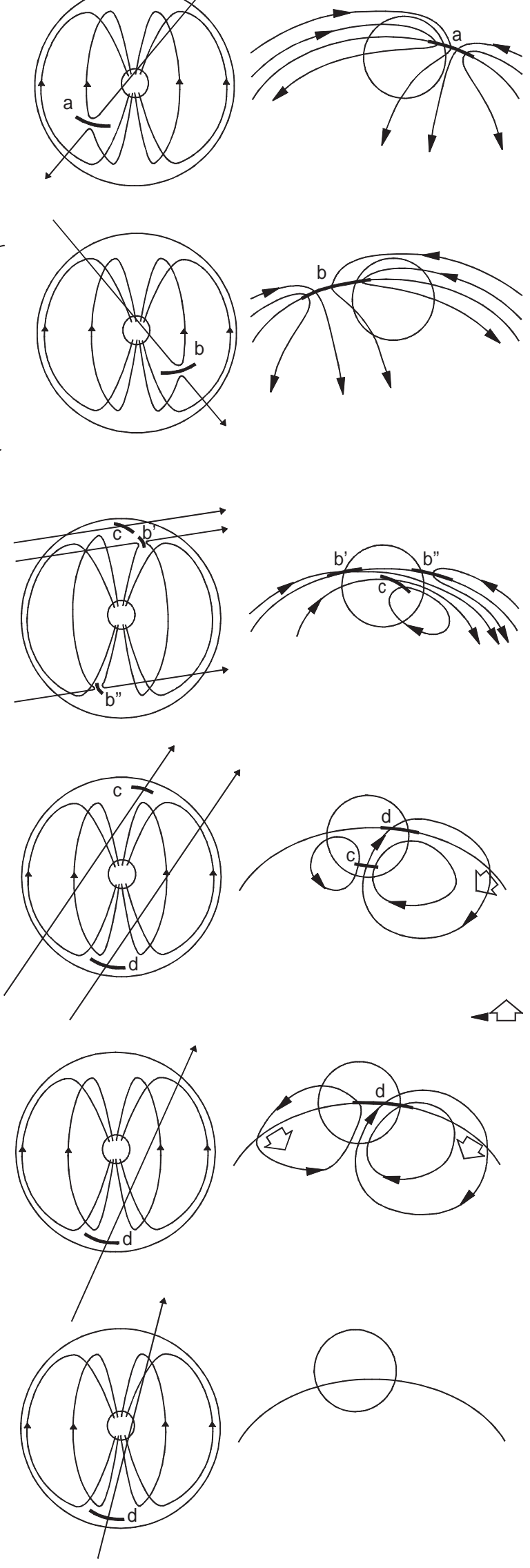

Fig. 7a-f. A series of schematics for a $08: 25$; b 08:40; c 09:00; d 09:07 (although, in fact this situation is unlikely to be present at all); e 09:10; f 09:14. The left hand plots are cross sections of the magnetosphere in a plane parallel to the $X Z$ plane, viewed form dusk with the Sun to the left. The centre plots are views from the Sun and the right hand plots are views of the Northern Hemisphere ionosphere from above with noon to the top, dawn to the right and dusk to the left. Note that in the middle plots the lobe reconnection sites (c and d) are shown, but lobe and overdraped lobe field lines are omitted for clarity. Reconnection sites are labelled $a, b, c$ and $d$ and are dots in the lefthand figures and solid lines in the centre figures: their projections into the Northern Hemisphere ionosphere are solid lines in the right-hand figures. Lines with arrows are magnetic field lines in the left and centre figures, and flow stream lines in the right-hand figures. The circle shows the field-ofview of the $630 \mathrm{~nm}$ all-sky camera at Longyearbyen 
the merging gap (labelled a) to the west of Svalbard. The weakly negative $B_{y}$ component at this time moves the newly-opened field lines to the east, but we suggest that this is not sufficient to bring high precipitation fluxes into most of the camera f.o.v., and the brightest $630 \mathrm{~nm}$ aurora (A) would have been to the west of the f.o.v. This thus can explain the situation seen in image 1. The low intensity band would then be the low-latitude boundary layer, LLBL (on either closed or open field lines) to the east of the merging gap.

Figure $7 \mathrm{~b}$ is for $08: 40$ (corresponding to WIND observations at about $08: 15$ ), for which the $B_{y}$ component has changed polarity giving $B_{z}<0, B_{y}>0$ and $B_{x}<0$ and the IMF orientation shown. For this, and all subsequent times, the IMF makes a typical garden hose angle near $45^{\circ}$ degrees in the $X Y$ plane and we suggest this favours reconnection more to the dawnside that in Fig. 7a. The aurora A does not migrate eastward across the noon meridian, but a new form $\mathrm{C}$ expands from the east and so we suggest that the $\mathrm{X}$-line a has ceased reconnecting and a new one $b$ has formed and spread into the f.o.v. from the east. The polarity change in IMF $B_{y}$ was seen by WIND at 08:05, for which the onset of the easterly aurora $C$ would be about 08:30 (it is first seen in the camera f-o-v at 08:38) and the westerly aurora A would fade over the subsequent 10-20 min, as observed.

Figure $7 \mathrm{c}$ is for 09:00 (corresponding to 08:35 at WIND) for which the $B_{z}$ component has changed polarity giving $B_{z}>0, B_{y}>0$ and $B_{x}<0$. The elevation angle $\phi$ of the IMF in the $Z X$ plane (between $-70^{\circ}$ and $-90^{\circ}$ in GSM) allows it to be draped over the northern winter lobe such that, despite the dipole tilt, a lobe reconnection site $\mathrm{c}$ is possible there. This produces field lines that initially convect sunward and have one of the topologies suggested by Cowley $(1981,1983)$ and which were called "overdraped lobe" by Crooker (1992). The large $B_{y}$ component at this time means that the ionospheric footprint of field lines reconnected by $\mathrm{c}$ would move strongly westward as well as slightly sunward. The rotation of the IMF has caused the lowlatitude reconnection $\mathrm{X}$-line $\mathrm{b}$ to split into two small parts $b^{\prime}$ and $b^{\prime \prime}$ which have rotated to higher magnetic latitudes near the cusp, as suggested for the anti-parallel reconnection hypothesis by Crooker (1979). The presence of $b^{\prime}$ is indicated by the maintenance of the aurora $\mathrm{C}$ to the east of Svalbard, although intensities may be lower as the open field lines produced by $b^{\prime}$ thread the boundary further away from the high density sheath at the nose of the magnetosphere than did those produced by $b$ in Fig. 7b (see Lockwood, 1997). However the curvature ("tension") force will tend to bring these back towards the dayside slightly, allowing some moderate precipitation fluxes to be maintained. The field lines connected to the Northern Hemisphere in the outflow region from $b^{\prime \prime}$ will be moved away from the nose in the antisunward direction and so fluxes will be lower and auroral intensities lower. The existence of $b^{\prime \prime}$ is, however, indicated by the brief flaring of aurora $E$ in the small erosion event to the west of Svalbard in image 3 of Fig. 6. In addition, we could associate the formation of event $\mathbf{J}$ in image 7 of Fig. 6 with a brief re-activation of $b^{\prime \prime}$ during the brief swing to southward IMF seen by WIND around 08:44. Although the production of new open field lines by $b^{\prime \prime}$ would only last 1 or $2 \mathrm{~min}$, the precipitation (and this event $\mathrm{J}$ ) would remain until the newly opened field lines were swept into the tail. The lobe reconnection explains the formation of the five southwestward moving events discussed in the previous section (B, F, G, H and I). The formation of the X-line c is first indicated by the formation of auroral form B and of the type 2 aurora that breaks away from the poleward edge of the type 1 . These occur at 08:49, corresponding to 08:24 in the WIND observations when the IMF first turned northward. Lobe reconnection reconfigures old open flux (which thread the magnetopause far down tail and in which no precipitation is seen at low altitudes) to make overdraped lobe flux which threads the magnetopause sunward of the lobe reconnection site and down which high magnetosheath fluxes will precipitate.

In Figs. 7d, e and f, the reconnection X-lines $b^{\prime}$ and $b^{\prime \prime}$ have disappeared and so no more open flux is being generated by low-latitude reconnection. The auroral form to the east of Svalbard, C, has almost disappeared in image 8, its final fade beginning at about 09:18. Given that the last field lines to be opened by this reconnection site will continue to experience high fluxes of magnetosheath ions and electrons for at least $10 \mathrm{~min}$ after reconnection, this suggests that the $\mathrm{X}$-line $\mathrm{b}^{\prime}$ ceased reconnecting some time before $09: 10$, which corresponds to WIND observations at about 08:45, when the IMF clock angle has decreased to near $55^{\circ}$.

It is not unambiguously clear from the data if lobe reconnection in the Southern Hemisphere (at d) commences before or after that in the Northern Hemisphere (at c) ceases. Figure $7 d$ assumes that it is before, but this stage may never be present if this is not the case. It is, however, included here for completeness. The first evidence for the re-closure of overdraped lobe flux is the arrival of the first of the south-west drifting features at the equatorward edge of the auroral band at about $09: 10$. The last of the southwest drifting events, I, formed before this at 09:05. This implies that, infact, c may well have ceased reconnecting before $\mathrm{d}$ commenced and the phase shown in Fig. 7d was never actually present. Were the reconnection at the lobe sites $\mathrm{c}$ and $\mathrm{d}$ to take place at the same rate, the amount of overdraped lobe flux would remain constant, however, the rotation of the IMF towards northward (increasing $\phi$ ) will increasingly favour the summer hemisphere and so $d$ will start to dominate over $\mathrm{c}$ and the amount of overdraped lobe flux will decrease. Figure 5 shows that peak latitudinal width of the $630 \mathrm{~nm}$ aurora is reached at about 09:08, corresponding to WIND observations at about $08: 43$, close to the time that the IMF elevation $\phi$ increases over a suggested threshold of about $-60^{\circ}$ for the first time. The right-hand panel in Fig. $7 d$ shows the situation which would exist shortly after the formation of reconnection line $\mathrm{d}$, if $\mathrm{c}$ were still dominant. The reconnection at $\mathrm{c}$ would drive a weak dusk lobe cell as well as the larger dawn cell because $B_{y}$, although still positive, is decreasing in magnitude. There is also a flow 
stream line which reflects the re-closure of overdraped flux at $d$. This streamline crosses a non-reconnecting ("adiaroic", see Siscoe and Huang, 1985) segment of the boundary where flux, plasma and the boundary all move together poleward, as shown by the large arrow.

Figure $7 \mathrm{e}$ is for $09: 10$ (corresponding to roughly 08:45 at WIND) for which both the clock and the elevation angles have changed as the IMF turns more northward to the orientation shown. The reconnection at $d$ is now closing overdraped field lines and causing the observed poleward motion of the equatorward band of the aurora, while events formed by c (before it ceased reconnection) are still migrating to the south and west (forms F, G, H and I). Figure 7f marks the end of this process when the last of the overdraped flux is re-closed. The $\mathrm{X}$-line $\mathrm{d}$ is now purely reconnecting the Southern Hemisphere lobe flux and is not connected at all to the Northern Hemisphere. Thus all directly reconnectiondriven auroral luminosity ceases on a highly contracted oval. This is close to happening in image 8 of Fig 6 . The loss of overdraped flux is also consistent with the increasingly shorter lifetimes of the equatorward-moving patches as they have a shorter transit time between the merging gaps $\mathrm{c}$ and $\mathrm{d}$.

\section{Discussion and conclusions}

We have presented some observations of the interplanetary magnetic field and of the associated dayside cusp/ cleft aurora. The rotation of the IMF to northward caused the poleward contraction of the aurora and the appearance of type 2 aurora at the poleward edge of the type 1 (southward-IMF) aurora. This is consistent with previous observations reported by Sandholt et al. (1996, 1998a,b) and Øieroset et al. (1997) and with a lobe reconnection site which initially mapped to the openclosed field line boundary, as predicted by Øieroset $e t$ al. (1997). The type 2 aurora subsequently developed into a series of five events which moved west and equatorward.

The latitudinal width of the cusp/cleft aurora would increase as the lobe reconnection generates overdraped lobe flux. The rate at which this flux is moved away from near noon (largely towards dawn because of the dominant positive $B_{y}$ component of the IMF) by the tension force and the sheath flow would be relatively slow, in which case the poleward motion of the poleward edge of the aurora reflects the lobe reconnection rate. The poleward edge moves from a zenith angle of $50^{\circ}$ to the south at $08: 45$ to $60^{\circ}$ to the north at $09: 06$, for an assumed emission height of $250 \mathrm{~km}$ this corresponds to a motion over $408 \mathrm{~km}$ in $21 \mathrm{~min}$, i.e. an average speed of $v=325 \mathrm{~m} \mathrm{~s}^{-1}$, corresponding to a reconnection rate, mapped into the ionosphere, of $E=v B_{i}=16 \mathrm{mV} \mathrm{m}^{-1}$.

There is evidence in this case that overdraped lobe flux was lost at the equatorward edge of the cusp/cleft aurora. This means that the overdraped lobe flux was reconnected in the Southern Hemisphere to become closed flux, as suggested by Crooker (1992), Song and Russell (1992) and Song et al. (1994) as a source of magnetosheath plasma in a northward-IMF, closed LLBL. There are two pieces of evidence for this. Firstly, the type 2 aurora events propagate south and west (consistent with the observed positive IMF $B_{y}$ ) and were seen, in the all-sky camera data, to disappear at the equatorward edge of the pre-existing type 1 aurora to the west of Svalbard. Secondly, as the IMF elevation angle $\phi$ increased, the width of the cusp/cleft aurora decreased, implying the loss of overdraped lobe flux. The maximum width of the cusp/cleft aurora was achieved at about 09:08, corresponding to WIND observations at about $08: 43$, very close to the time that the IMF elevation $\phi$ increased to near $(-\delta)$ for the first time. We interpret this as the threshold at which we would expect the Southern Hemisphere lobe reconnection (which destroys Northern Hemisphere overdraped lobe flux) to have started to dominate over Northern Hemisphere lobe reconnection (which generates the Northern Hemisphere overdraped lobe flux).

The evolution of the cusp/cleft aurora was therefore consistent with lobe reconnection in both hemispheres. Furthermore, the ratio of the reconnection rates at the two lobes appears to have been controlled by the IMF elevation angle $\phi$ for the prevailing dipole tilt of the Earth's magnetic field.

Acknowledgements. The authors are grateful to B. Lybekk of Oslo University for his help with the optical measurements and to P.E. Sandholt (also of Oslo University) for discussions and for bringing this event to our attention. We also thank M. Hapgood of RAL for the Tsyganenko model predictions. The auroral observation programme on Svalbard is supported by the Norwegian Research Council (Norges Forskningsråd) and the Norwegian Polar Research Institute and UNIS grant 9/963. This work was carried out while ML was at UNIS in April 1997 as a guest lecturer. We thank K. Ogilvie and R.P. Lepping for, respectively, the SWE and MFI data from the WIND satellite which were processed and plotted for us by M.Wild of World Data Centre C1 at RAL.

Topical Editor K.-H. Glassmeier thanks P. Song and M. Oieroset for their help in evaluating this paper.

\section{References}

Anderson, B. J., T. D. Phan, and S. A. Fuselier, Relationships between plasma depletion and subsolar reconnection, J. Geophys. Res., 102., 9531-9542, 1997.

Burch, J. L., Rate of erosion of dayside magnetic flux based on a quantitative study of polar cusp latitude on the interplanetary magnetic field, Radio Sci., 8, 955-961, 1973.

Burke, W. J., M. C. Kelley, R. C. Sagalyn, M. Smiddy, and S. T. Lai, Polar cap electric field structures with northward interplanetary magnetic field, Geophys. Res. Lett., 6, 21-24, 1979.

Candidi, M., H. W. Kroehl, and C. -I. Meng, Intensity distribution of dayside polar soft electron precipitation and the IMF, Planet. Space Sci., 31, 489, 1983.

Carbary, J. F., and C. -I. Meng, Correlation of cusp width with AE(12) and Bz, Planet. Space Sci., 36, 157-161, 1988

Cowley, S. W. H., Magnetospheric and ionospheric flow and the interplanetary magnetic field, in Physical basis of the Ionosphere in the Solar-Terrestrial System, AGARD CP-295, pp. 4/1-4/14, 1981.

Cowley, S. W. H., Interpretation of observed relations between solar wind characteristics and effects at ionospheric altitudes, in 
High-Latitude Plasma Physics, Ed. B. Hultqvist and T. Hagfors, pp. 225-249, Plenum Press, 1983.

Cowley, S. W. H., and M. Lockwood, Excitation and decay of solar-wind driven flows in the magnetosphere-ionosphere system, Annales Geophys. Res., 10, 103-115, 1992.

Cowley, S. W. H., J. P. Morelli, and M. Lockwood, Dependence of convective flows and particle precipitation in the high-latitude dayside ionosphere on the $X$ and $Y$ components of the interplanetary magnetic field, J. Geophys. Res., 96, 5557-5564, 1991.

Crooker, N. U., Dayside merging and cusp geometry, J. Geophys. Res., 84, 951, 1979.

Crooker, N. U., Reverse convection, J. Geophys. Res., 97, 19 36319 372, 1992.

Crooker, N. U., and F. J. Rich, Lobe-cell convection as a summer phenomenon, Geophys. Res., 98, 13 403-13 407, 1993.

Cumnock, J. A., R. A. Heelis, and M. R. Hairston, Response of the ionospheric convection pattern to a rotation of the interplanetary magnetic field on January 14 1988, J. Geophys. Res., 97, 19 449-19 460, 1992.

Dungey, J. W., The structure of the exosphere of adventures in velocity space, in Geophysics, The Earth's Environment, Ed. C. DeWitt, J. Hieblot, and A. Lebeau, pp. 505-550, Gordon and Breach, New York, 1963.

Farrugia, C. J., M. P. Freeman, L. F. Burlaga, R. P. Lepping and K. Takahashi, The Earth's magnetosphere under continued forcing: substorm activity during the passage of an interplanetary magnetic cloud, J. Geophys. Res., 98, 7657-7671, 1993.

Fox, N. J., M. Lockwood, S. W. H. Cowley, M. P. Freeman, E. Friis-Christensen, D. K. Milling, M. Pinnock, and G. D. Reeves, EISCAT observations of unusual flows in the morning sector associated with weak substorm activity, Annales Geophys. 12, 541-553, 1994.

Freeman, M. P., C. J. Farrugia, L. F. Burlaga, M. R. Hairston, M. E. Greenspan, J. M. Ruohoniemi, and R. P. Lepping, The interaction of a magnetic cloud with the earth: ionospheric convection in the Northern and Southern Hemispheres for a wide range of quasi-steady interplanetary magnetic field conditions, J. Geophys. Res., 98, 7633-7655, 1993.

Fuselier, S., B. J. Anderson, and T. G. Onsager, Electron and ion signatures of field line topology at the low shear magnetopause, J. Geophys. Res., 100, 11805-11814, 1995.

Fuselier, S., B. J. Anderson, and T,G, Onsager (1997) Electron and ion signatures of field line topology at the low shear magnetopause, J. Geophys. Res., 102, 4847-4863, 1997.

Gosling, J. T., M. F. Thomsen, S. J. Bame, R. C. Elphic, and C. T. Russell, Plasma flow reversals at the dayside magnetopause and the origin of asymmetric polar cap convection, J. Geophys. Res., 95, 8073-8084, 1990.

Gosling J. T., M. F. Thomsen, S. J. Bame, R. C. Elphic, and C. T, Russell, Observations of reconnection of interplanetary and lobe magnetic field lines at the high-latitude magnetopause, J. Geophys. Res., 96, 14 097-14 106, 1991.

Heelis, R. A., The effects of interplanetary magnetic field orientation on dayside high-latitude convection, J. Geophys. Res., 89 , 2873, 1984.

Horwitz, J. L., and S. -I. Akasofu, The response of the dayside aurora to sharp northward and southward transitions of the interplanetary magnetic field and to magnetospheric substorms, J. Geophys. Res., 82, 2723-2734, 1977.

Kessel, et al., Evidence of high-latitude reconnection during northward IMF: Hawkeye observations, Geophys. Res. Lett., 23, 583-586, 1996.

Knipp, D. J., et al., Ionospheric convection response to slow, strong variations in a northward interplanetary magnetic field: a case for study for January 14 1988, J. Geophys. Res., 98, 19 273$19292,1993$.

Lockwood, M., The location and characteristics of the reconnection $\mathrm{X}$-line deduced from low-altitude satellite and ground-based observations: 1. Theory, J. Geophys. Res., 100, 21 791-21 802, 1995.
Lockwood, M., The relationship of dayside auroral precipitations to the open-closed separatrix and the pattern of convective flow, J. Geophys. Res., 102, 17 475-17 487, 1997.

Lockwood, M., and S. W. H. Cowley, Ionospheric convection and the substorm cycle, in Substorms 1, Proceedings of the First International Conference on Substorms, ICS-1, Ed C. Mattock, ESA-SP-335, 99-109, European Space Agency Publications, Nordvijk, The Netherlands, 1992.

Lockwood, M., S. W. H. Cowley, and M. P. Freeman, The excitation of plasma convection in the high latitude ionosphere, J. Geophys Res., 95, 7961-7971, 1990.

Lockwood, M., H. C. Carlson, and P. E. Sandholt, The implications of the altitude of transient $630 \mathrm{~nm}$ dayside auroral emissions, J. Geophys. Res., 98, 15 571-15 587, 1993.

Maezawa, K., Magnetosphere convection induced by the positive and negative $\mathrm{Z}$ components of the interplanetary magnetic field: quantitative analysis using polar cap magnetic records, J. Geophys. Res., 81, 2289-2303, 1976.

Newell, P. T., and C. I. Meng, Cusp width and $B_{z}$ : observations and a conceptual model, J. Geophys. Res., 92, 13 673-13 678, 1987.

Newell, P. T., and C. -I. Meng, Dipole tilt effects on the latitude of the cusp/low-latitude boundary layer, J. Geophys. Res., 94, 6949, 1989.

Newell, P. T., C. -I. Meng, D. G. Sibeck, and R. Lepping, Some lowaltitude cusp dependencies on the interplanetary magnetic field, J. Geophys. Res., 94, 8921-8927, 1989.

Øieroset, M., Sandholt, P. E., Denig, W. F., and Cowley, S. W. H., Northward interplanetary magnetic field cusp aurora and highlatitude magnetopause reconnection, J. Geophys. Res., 102, $11349,1997$.

Onsager T. G., C. A. Kletzing, J. B. Austin, and H. MacKiernan, Model of magnetosheath plasma in the magnetosphere: cusp and mantle particles at low-altitudes, Geophys. Res. Lett., 20, 479-482, 1993.

Paschmann, G., B. Sonnerup, I. Papamastorakis, W. Baumjohann, N. Sckopke, and H. Lühr, The magnetopause and boundary layer for small magnetic shear: convection electric fields and reconnection, Geophys. Res. Lett., 17, 1829-1832, 1990.

Phan, T. D., G. Paschmann, and B. U. Ö. Sonnerup, Low latitude dayside magnetopause and boundary layer for high magnetic shear 2. Occurrence of magnetic reconnection, J. Geophys. Res., 101, 7817, 1996.

Reiff, P. H., Sunward convection in both polar caps, J. Geophys. Res., 87, 5976-5980, 1982.

Russell, C. T., The configuration of the magnetosphere, in Critical Problems of Magnetospheric Physics, Ed E.R. Dyer, p.1, National Academy of Sciences, Washington, 1972.

Sandholt, P. E., Auroral electrodynamics at the cusp/cleft poleward boundary during northward interplanetary magnetic field, Geophys. Res. Lett., 18, 805-808. 1991.

Sandholt, P. E., C. J. Farrugia, M. Øieroset, P. Stauning, and S. W. H. Cowley, Auroral signature of lobe reconnection, Geophys. Res. Lett., 23, 1725-1728, 1996.

Sandholt, P. E., C. J. Farrugia, J. Moen, and B. Lybekk, The dayside aurora and its regulation by the interplanetary magnetic field, in Polar Cap Boundary Phenomena, Ed. J. Moen, A. Egeland and M. Lockwood, NATO ASI Series C, Vol. 509, pp. 189-208, Kluwer, Dordrecht, 1998a.

Sandholt, P. E., C. J. Farrugia, J. Moen, and S. W. H. Cowley, Dayside auroral configurations: responses to southward and northward rotations of the interplanetary magnetic field, J. Geophys. Res., 103, 20279-20295, 1998b.

Scurry, L., C. T. Russell, and J. T. Gosling, A statistical study of accelerated flow events at the dayside magnetopause, J. Geophys. Res., 99, 14 815-14 829, 1994.

Siscoe, G. L., and T. S. Huang, Polar cap inflation and deflation, J. Geophys. Res., 90, 543, 1985.

Song, P., and C. T. Russell, Model of the formation of the lowlatitude boundary layer for strongly northward interplanetary magnetic field, J. Geophys. Res., 97, 1411-1420, 1992. 
Song, P., T. E. Holzer, C. T. Russell, and Z, Wang, Modelling the low-latitude boundary layer with reconnection entry, Geophys. Res. Lett., 21, 625-628, 1994.

Weiss, L. A., P. H. Reiff, E. J. Weber, H. C. Carlson, M. Lockwood, and W. K. Peterson, Flow-aligned jets in the magnetospheric cusp: results from the Geospace Environment Modelling pilot programme, J. Geophys. Res., 100, 7649-7660, 1995.

Woch, J., and R. Lundin, Magnetosheath plasma precipitation in the polar cusp and its control by the interplanetary magnetic field, J. Geophys. Res., 97, 1421-1430, 1992.
Wygant, J. R., R. B. Torbert, and F. S. Mozer, Comparison of S3-2 polar cap potential drops with the interplanetary magnetic field and models of magnetopause reconnection, J. Geophys. Res., 88, 5727, 1983.

Zanetti, L. J., T. A. Potemra, T. Iijima, W. Baumjohann, and P. F. Bythrow, Ionospheric and Birkeland current distributions for northward interplanetary magnetic field: inferred polar cap convection, J. Geophys. Res., 89, 7453-7458, 1984. 